\title{
ACTIVIDAD INHIBITORIA in vitro DE LOS EXTRACTOS ACUOSOS DE LOS FRUTOS DE Hylocereus megalanthus Y Passiflora tripartita var. mollisima SOBRE LAS ENZIMAS $\alpha$-AMILASA Y $\alpha$-GLUCOSIDASA
}

\author{
Erick Raúl Coral Caycho ${ }^{* a}$, María Rosario Calixto Cotos ${ }^{\mathrm{b}}$, \\ María Mercedes Soberón Lozano ${ }^{c}$
}

\begin{abstract}
RESUMEN
La pitahaya amarilla (Hylocereus megalanthus) y el tumbo serrano (Passiflora tripartita var. mollisima) son frutos cultivados en Perú. El objetivo de este estudio fue evaluar la propiedad hipoglicemiante de estos frutos mediante la inhibición in vitro de las enzimas $\alpha$-amilasa y $\alpha$-glucosidasa. Los frutos fueron despulpados y liofilizados, y luego de preparar los respectivos extractos acuosos, se determinó el contenido de polifenoles totales (TPC) mediante el método de Folin-Ciocalteu. La actividad inhibitoria se determinó mediante el $\mathrm{IC}_{50}$ y se evaluó el tipo de inhibición utilizando $0,25-2 \mathrm{mg} / \mathrm{mL}$ y $0,02-0,28 \mathrm{mg} / \mathrm{mL}$ del extracto del tumbo serrano sobre la $\alpha$-amilasa y $\alpha$-glucosidasa, respectivamente. Para la pitahaya se empleó 4-64 mg/ml y $0,8-25,6 \mathrm{mg} / \mathrm{mL}$ sobre la $\alpha$-amilasa y $\alpha$-glucosidasa, respectivamente. Los TPC para el tumbo serrano y pitahaya amarilla fueron de 614,67 y $16,17 \mathrm{mg} / 100 \mathrm{~g}$ de muestra, respectivamente, expresados en equivalente de ácido gálico. El extracto acuoso de tumbo serrano inhibió a las enzimas $\alpha$-amilasa y $\alpha$-glucosidasa (tipo no competitiva mixta) con un $\mathrm{IC}_{50}$ de 1719,18 y $77,68 \mu \mathrm{g} / \mathrm{Ml}$, respectivamente, mientras que la pitahaya amarilla solo inhibió a la enzima $\alpha$-glucosidasa con un $\mathrm{IC}_{50}$ de $8692,4 \mu \mathrm{g} / \mathrm{mL}$ (tipo competitiva).
\end{abstract}

Palabras clave: Hylocereus megalanthus, Passiflora tripartita var. mollisima, inhibición enzimática, $\alpha$-amilasa, $\alpha$-glucosidasa.

\footnotetext{
${ }^{* a}$ Facultad de Odontología, Unidad de Posgrado-Maestría en Bioquímica UNMSM. Av. Germán Amézaga No 375

- Ciudad Universitaria, Cercado de Lima, Lima, Perú. erickcoral11@gmail.com

b Facultad de Química e Ingeniería Química, UNMSM, Ciudad Universitaria, Av. Venezuela. Lima-Perú.

c Centro de Investigación de Bioquímica y Nutrición, Facultad de Medicina. UNMSM. Av. Grau 755. Lima 1, Perú.
} 


\title{
In vitro INHIBITORY ACTIVITY OF AQUEOUS EXTRACTS OF FRUITS OF Hylocereus megalanthus AND Passiflora tripartita var. mollisima ON $\alpha$-AMYLASE AND $\alpha$-GLUCOSIDASE ENZYMES
}

\begin{abstract}
"Pitahaya amarilla" (Hylocereus megalanthus) and "tumbo serrano" (Passiflora tripartita var. mollisima) two fruits that grow in Peru. The aim of this study was to evaluate the hypoglycemic activity by in vitro inhibition of $\alpha$-amylase and $\alpha$-glucosidase enzymes. The fruits were pulped and lyophilized, and after the obtaining of aqueous extracts, the total phenolic content (TPC) was determined by the Folin-Ciocalteu method. Inhibitory activity was determined by $\mathrm{IC}_{50}$, and the type of inhibition was evaluated using $0,25-2 \mathrm{mg} / \mathrm{mL}$ and $0,02-0,28 \mathrm{mg} / \mathrm{mL}$ of the extract of tumbo serrano for $\alpha$-amylase and $\alpha$-glucosidase, respectively. For pitahaya amarilla, 4-64 $\mathrm{mg} / \mathrm{mL}$ and $0,8-25,6 \mathrm{mg} / \mathrm{mL}$ were used for each enzyme, respectively. The TPC for the tumbo serrano and pitahaya amarilla were 614,67 and $16,17 \mathrm{mg} / 100 \mathrm{~g}$ of sample, respectively, expressed as gallic acid equivalents. The aqueous extract of tumbo serrano inhibited the $\alpha$-amylase and $\alpha$-glucosidase (mixed non-competitive type) with an $\mathrm{IC}_{50}$ of 1719,18 and $77,68 \mu \mathrm{g} / \mathrm{mL}$ for each enzyme, respectively, while pitahaya amarilla only inhibited the $\alpha$-glucosidase with an IC50 of $8692,4 \mu \mathrm{g} / \mathrm{mL}$ (competitive type).
\end{abstract}

Key words: Hylocereus megalanthus, Passiflora tripartita var. mollisima, enzymatic inhibition, $\alpha$ - amylase, $\alpha$-glucosidase.

\section{INTRODUCCIÓN}

La diabetes mellitus (DM) es una enfermedad metabólica que se caracteriza por presentar niveles altos de glucosa, originando como consecuencia de ellos transtornos en el metabolito de carbohidratos, grasas y proteínas ${ }^{1}$. Hasta el año 2014, en el Perú, existía una prevalencia de $6,7 \%$ de personas, de 18 años de edad a más, con DM, de los cuales el tipo II es el más frecuente, constituyendo el 90 al 95\% de los diabéticos. En este tipo de diabetes se observa un defecto progresivo en la producción de la insulina, así como una insulinorresistencia principalmente en hígado y músculo lo que conlleva a niveles altos de glucosa en sangre ${ }^{2}$. Estos niveles altos ocasionan un daño oxidativo en varios tejidos y órganos del cuerpo debido a la ruptura del equilibrio entre las especies reactivas de oxígeno (EROS) y los sistemas de defensa antioxidante ${ }^{3}$.

En el Perú existe una gran variedad de plantas, a las cuales se les atribuyen distintas propiedades, que son empleadas por los pobladores para tratar distintas enfermedades. Entre ellas están el tumbo serrano (Passiflora tripartita var. mollisima) y la pitahaya amarilla (Hylocereus megalanthus) que crecen entre los 1100 a 3500 msnm. A ellas se les designan propiedades antiinflamatoria, antioxidante e hipoglicemiante, lo cual podría ser explicado por el contenido de compuestos fenólicos ${ }^{4}$. 
Loizzo et $a l .{ }^{5}$, en el 2019, identificaron los compuestos fenólicos presentes en el fruto del tumbo serrano, encontrando valores altos de catequinas y ácido sinapínico. De igual manera, la presencia de antioxidantes naturales, como las betalaínas, han sido encontrados en la cáscara y pulpa de frutos de distintas especies de Hylocereus ${ }^{6}$.

Se han reportado estudios donde los compuestos fenólicos (por ejemplo el ácido cafeico y ácido p-cumárico), presentes en algunas plantas, poseen efecto hipoglicemiante al inhibir enzimas que participan en la digestión de carbohidratos, como por ejemplo la $\alpha$-amilasa y $\alpha$-glucosidasa que juegan un papel importante en la digestión y que están relacionadas con el aumento de glucosa en el estado postprandial ${ }^{7}$. El tumbo serrano y la pitahaya amarilla, que según referencias contienen una considerable cantidad de polifenoles, podrían ser considerados alimentos con provecho terapéutico para los pacientes con diabetes.

Teniendo en cuenta la importancia de los compuestos fenólicos presentes en las plantas, el propósito de este estudio fue observar la posible actividad y modo inhibitorio de los extractos acuosos de los frutos mencionados sobre las enzimas $\alpha$-amilasa y $\alpha$-lucosidasa con el fin de verificar su posible uso como tratamiento adyuvante a los fármacos usados en la DM.

\section{PARTE EXPERIMENTAL}

\section{Reactivos}

Los reactivos $\alpha$-glucosidasa de Saccharomyces cerevisiae, $\alpha$-amilasa de páncreas porcino, 4-nitrofenil $\alpha$-D-glucopiranósido (pNPG), ácido 3,5 dinitrosalicílico, acarbosa y la D-(+)Maltosa monohidratada fueron adquiridos de Sigma - Aldrich.

\section{Material vegetal}

Los frutos del Passiflora tripartita var. mollisima (tumbo serrano) fueron recolectados en la provincia de Andahuaylas, departamento de Apurímac (2926 msnm), mientras los frutos de la Hylocereus megalanthus (pitahaya amarilla) fueron recolectados en la provincia de San Ignacio, departamento de Cajamarca (1324 msnm). Las dos plantas fueron identificadas en el herbario del Museo de Historia Natural de la Universidad Nacional Mayor de San Marcos. El tumbo serrano, con constancia $\mathrm{N}^{\circ}$ 226-USM-2019, fue determinado por el Mg. Asunción A. Cano Echevarría y la pitahaya amarilla, con constancia $N^{\circ} 238$-USM-2019, fue determinado por la Dra. Mónica Arakaki Makishi.

\section{Preparación de los extractos acuosos}

2,5 kg de Passiflora tripartita var. mollisima e Hylocereus megalanthus fueron lavados con agua bidestilada e hipoclorito de sodio al $5 \%$. Se les retiró la cáscara, seguido de un despulpado utilizando un colador de plástico para dejar la pulpa sin semillas quedándonos con $312 \mathrm{~g}$ de P. tripartita var. mollisima y $232 \mathrm{~g}$ de H. megalanthus. Las pulpas, así obtenidas, fueron liofilizadas en un equipo marca RIFICOR por 12 horas y almacenadas a $-25^{\circ} \mathrm{C}$, obteniendo pesos finales de 71,23 g de P. tripartita var. mollisima y 53,33 g de H. megalanthus con 
rendimientos de 22,83 y $22,98 \%$, respectivamente. Estas pulpas disueltas en agua bidestilada constituyen la muestra experimental para los siguientes análisis.

\section{Determinación de polifenoles totales}

La determinación de polifenoles totales se realizó de acuerdo a la técnica descrita por Calixto et al. ${ }^{8}$ (2018). Las muestras liofilizadas fueron disueltas en agua bidestilada hasta obtener una solución stock $(0,93 \mathrm{mg} / \mathrm{mL}$ y $32 \mathrm{mg} / \mathrm{mL}$ para la $P$. tripartita var. mollisima e $H$. megalanthus, respectivamente). Se mezcló $100 \mu \mathrm{L}$ de la solución stock con $150 \mu \mathrm{L}$ del reactivo Folin-Ciocalteu (diluido 1 en 3), luego de 5 minutos de reposo se añadió $150 \mu \mathrm{L}$ de carbonato de sodio al $20 \%$ y $600 \mu \mathrm{L}$ de agua bidestilada, la mezcla final se dejó reposar en oscuridad por 30 minutos y luego leída en espectrofotómetro a $760 \mathrm{~nm}$. Se realizó una curva de calibración utilizando ácido gálico como referencia a concentraciones de $1-7,5 \mu \mathrm{g} / \mathrm{mL}\left(\mathrm{y}=0.0916 \mathrm{x}+0.008, \mathrm{R}^{2}=0.9995\right)$ y $\operatorname{los}$ resultados fueron expresados en equivalentes de ácido gálico (EAG) en mg/100g de muestra liofilizada.

\section{Actividad inhibitoria de la enzima $\alpha$-amilasa.}

La inhibición de la enzima se llevó a cabo siguiendo la técnica usada por Wang et al. ${ }^{9}$ (2016) con ligeras modificaciones. Se preparó buffer fosfato de sodio 0,1 M (pH 6,9 con $\mathrm{NaCl} 0,1 \mathrm{M}$ ) y almidón de papa al 1\% (disuelto en buffer) como sustrato. Las muestras fueron preparadas a distintas concentraciones, se mezcló $120 \mu \mathrm{L}$ de la muestra con $30 \mu \mathrm{L}$ de almidón, $100 \mu \mathrm{L}$ de buffer, $90 \mu \mathrm{L}$ de agua bidestilada y $60 \mu \mathrm{L}$ de enzima $\alpha$-amilasa (3 Unid/ $\mathrm{mL}$ ); después de 8 minutos de incubación a $37^{\circ} \mathrm{C}$ se detuvo la reacción con $200 \mu \mathrm{L}$ de ácido 3,5 dinitrosalicílico y $900 \mu \mathrm{L}$ de agua bidestilada, la mezcla se volvió a incubar pero esta vez a $100{ }^{\circ} \mathrm{C}$ de temperatura durante 5 minutos y se enfrió con agua helada. La absorbancia fue determinada a $540 \mathrm{~nm}$.

Para la preparación del blanco se reemplazó la enzima por el buffer. El control fue preparado reemplazando los extractos por agua bidestilada. Se utilizó como inhibidor estándar a la acarbosa. El porcentaje de inhibición de las muestras y acarbosa sobre la enzima $\alpha$-amilasa fueron calculados con la siguiente fórmula.

$$
\text { Inhibición (\%) }=\left(\left(A_{\text {control }}-A_{\text {muestra }}\right) / A_{\text {muestra }}\right) \times 100
$$

El valor de $\mathrm{IC}_{50}$ se definió como la concentración necesaria para inhibir el 50\% de la actividad enzimática. Este valor se obtuvo al graficar los valores de \% de inhibición versus los valores de concentración de los extractos.

\section{Actividad inhibitoria de la enzima $\alpha$-glucosidasa}

Se realizó con el método descrito por Wang et al. ${ }^{9}$ (2016). Las muestras se prepararon a distintas concentraciones. A $20 \mu \mathrm{L}$ de la muestra se le adicionó $80 \mu \mathrm{L}$ de buffer fosfato de sodio $0,1 \mathrm{M}$ (pH 6,8), $120 \mu \mathrm{L}$ de pNPG $1 \mathrm{mM}$ como sustrato, $170 \mu \mathrm{L}$ de agua bidestilada y $10 \mu \mathrm{L}$ de enzima $\alpha$-glucosidasa (3 Unid/mL); después de 15 minutos de incubación a temperatura ambiente se detuvo la reacción con $600 \mu \mathrm{L}$ de $\mathrm{NaOH} 1 \mathrm{M}$. La absorbancia fue determinada a $405 \mathrm{~nm}$. 
El blanco fue preparado cambiando la enzima por el buffer, mientras para el control se cambió los extractos por agua bidestilada. La acarbosa se utilizó como inhibidor estándar. El porcentaje de inhibición de las muestras y acarbosa sobre la enzima $\alpha$-glucosidasa fueron calculados con la siguiente fórmula.

$$
\text { Inhibición (\%) }=\left(\left(A_{\text {control }}-A_{\text {muestra }}\right) / A_{\text {muestra }}\right) \times 100
$$

El valor de $\mathrm{IC}_{50}$ se definió como la concentración necesaria para inhibir el 50\% de la actividad enzimática. Este valor se obtuvo al graficar los valores de \% de inhibición versus los valores de concentración de los extractos.

\section{Comportamiento de inhibición de las enzimas $\alpha$-amilasa y $\alpha$-glucosidasa}

Para analizar el comportamiento inhibitorio que ejercen los extractos acuosos sobre las enzimas se utilizó el diagrama de Lineweaver-Burk. Se utilizó el mismo procedimiento antes descrito para la determinación de actividad de las enzimas, el sustrato de cada enzima fue preparado a distintas concentraciones y se mantuvo constante la concentración de las muestras. La acarbosa también fue utilizada para comparar el modo de inhibición de los frutos estudiados sobre las enzimas.

\section{Análisis estadístico}

Los resultados se expresaron como la media y la desviación estándar de tres réplicas de ensayo. Para el test de normalidad se usó la prueba de Shapiro Wilk seguido de la prueba paramétrica de ANOVA de comparaciones múltiple con post Hoc de Tukey.

\section{RESULTADOS Y DISCUSIÓN}

\section{Contenido de polifenoles totales}

Los resultados muestran que el extracto acuoso de la Passiflora tripartita var. mollisima presentó una cantidad 38 veces mayor de polifenoles que la Hylocereus megalanthus (tabla 1), este valor obtenido en la $P$. tripartita var. mollisima fue semejante al encontrado por Contreras et al. ${ }^{10}$ (2011) donde el extracto metanólico de la pulpa reportó un valor de $635 \pm$ 2,71 mg EAG/100g, cuyo valor fue cercano a nuestro estudio; en tanto Rojano et al. ${ }^{11}$ (2012) reportaron una cantidad de polifenoles mayor en el extracto acuoso de la pulpa de $P$. tripartita var. mollisima 5012,8 $\pm 68,2 \mathrm{mg}$ EAG/100g de muestra, esta diferencia de valores podría explicarse debido a la manera como se obtuvo el extracto con el uso de un homogeneizador y un agitador por un tiempo de 16 horas.

Otros frutos del género Passiflora, conocidos por su buena capacidad antioxidante, son la granadilla y la maracuyá. Carvajal et al. ${ }^{12}$ (2011) trabajaron estos frutos, también bajo la forma de extractos acuosos, reportando valores totales de polifenoles de 204,54 mg EAG/100g para la granadilla y $282,16 \mathrm{mg}$ EAG/100g para maracuyá. Siendo valores menores a los obtenidos en el presente estudio. 
Tabla 1. Cantidad de polifenoles totales en los extractos acuosos de P. tripartita var. mollisima e H. megalanthus.

\begin{tabular}{cc}
\hline & Cantidad de polifenoles totales \\
\hline Passiflora tripartita var. mollisima & $614,67 \pm 5,03$ \\
Hylocereus megalanthus & $16,17 \pm 0,32$ \\
\hline
\end{tabular}

* Resultados expresados mg EAG/ 100g de extracto \pm DS

Los valores de polifenoles totales para la pitahaya amarilla (Hylocereus megalanthus) obtenidas en el presente trabajo, son más bajos que el valor reportado por el tumbo serrano (P. tripartita var. mollisima) (tabla 1). Sin embargo no están tan lejos a los obtenidos por De Lima et al. ${ }^{13}$ (2013) quienes trabajaron con la pulpa de varias especies de pitahaya ( $H$. megalanthus, $H$. undatus, $H$. costaricencis e $H$. setaceus). Para ello, realizaron una primera extracción con metanol y luego el residuo fue extraído con acetona, para finalmente juntar los sobrenadantes obtenidos. Sus resultados mostraron que la pitahaya púrpura (H. costaricencis) tuvo una mayor cantidad de polifenoles $(24,71 \mathrm{mg}$ EAG/100g de muestra) mientras que la pitahaya roja (H. undatus) y la pitahaya amarilla (H. megalanthus), obtenidas de un banco de germoplasma mostraron los niveles más bajos (11,45 y 11,94 mg EAG/100g de muestra, respectivamente).

Otro estudio de pitahaya amarilla (Hylocereus megalanthus) mostró que el extracto etanólico de la pulpa poseía una cantidad de $150 \mathrm{mg}$ EAG/100g de muestra ${ }^{14}$. El extracto etanólico de la pulpa de pitahaya roja, otra especie del género Hylocereus, tuvo un valor de $28,65 \mathrm{mg}$ EAG/100g de muestra ${ }^{15}$.

Esta diferencia de valores podría explicarse por el tipo de solvente utilizado para la preparación del extracto, lo que supondría que los polifenoles presentes en los mencionados frutos no son únicamente polares.

\section{Inhibición de las enzimas $\alpha$-amilasa y $\alpha$-glucosidasa}

La inhibición de estas enzimas es uno de los principales objetivos de los fármacos utilizados en el tratamiento de la DM. El valor de $\mathrm{IC}_{50}$ del tumbo serrano (Passiflora tripartita var. mollisima) como parámetro de inhibición para la $\alpha$-glucosidasa mostró valores cercanos a los obtenidos al de la acarbosa que es un fármaco utilizado para el tratamiento de DM tipo II (tabla 2). Sin embargo, con la muestra de pitahaya amarilla el valor de $\mathrm{IC}_{50}$ fue mayor. Por otro lado, el $\mathrm{IC}_{50}$ del tumbo serrano ( $P$. tripartita var. mollisima) mostró un valor muy alto de inhibición para la $\alpha$-amilasa. No se observó efecto inhibitorio de la pitahaya amarilla sobre esta enzima. Rey et al. ${ }^{16}$ (2015) reportaron valores de $\mathrm{IC}_{50}$ de la acarbosa muy elevados para las enzimas $\alpha$-glucosidasa y $\alpha$-amilasa $\left(773,2\right.$ y $229,6 \mu \mathrm{g} / \mathrm{mL}$, respectivamente). $\mathrm{El} \mathrm{IC}_{50}$ obtenido en nuestro estudio reportó valores muy elevados comparados con otras investigaciones debido a que el extracto acuoso obtenido consiguió mayormente la extracción de metabolitos polares, mientras que extractos obtenidos con solventes apolares y medianamente polares liberan otro tipo de metabolitos. La explicación a todos estos resultados del trabajo se debería también a la composición y tipos de polifenoles que tendría cada fruto en el extracto acuoso ${ }^{7}$. 
Estudios reportan que el efecto hipoglicemiante de los frutos de la familia Hylocereus no es debido a la capacidad de inhibir a las enzimas digestivas, sino a su capacidad de mejorar la resistencia a la insulina e incrementar los niveles de expresión de genes de los receptores del factor de crecimiento fibroblástico 21 (FGF21), el cual participa en la regulación del metabolismo de lípidos y glucosa, donde este FGF21 se encuentra elevado en pacientes diabéticos tipo $\mathrm{II}^{17}$.

Tabla 2. Valores de $\mathrm{IC}_{50}$ de extractos acuosos y control.

\begin{tabular}{lccc}
\hline & \multicolumn{3}{c}{$\boldsymbol{I C}_{\mathbf{5 0}}(\boldsymbol{\mu g} / \boldsymbol{m L})$} \\
\cline { 2 - 4 } & $\begin{array}{c}\boldsymbol{P} \text {. tripartita var. } \\
\text { mollisima }\end{array}$ & $\begin{array}{c}\text { Hylocereus } \\
\text { megalanthus }\end{array}$ & Acarbosa \\
\cline { 2 - 4 } $\boldsymbol{\alpha}$-amilasa & $1719,18 \pm 134,38^{\mathrm{a}}$ & $\mathrm{ND}$ & $15,59 \pm 0,86$ \\
$\boldsymbol{\alpha}$-glucosidasa & $77,68 \pm 8,27$ & $8692,4 \pm 128,2^{\mathrm{b}}$ & $68,04 \pm 1,17$ \\
\hline Resultados expresados en media \pm desviación estándar & & \\
a,b diferencia significativa con p-valor $<0,05$ & & \\
ND: no detectado &
\end{tabular}

Otra investigación llevada a cabo con la pulpa del fruto de la Passiflora subpeltata, denominada "granada de zorra", fue sometida a extracción con diferentes solventes (éter, cloroformo, acetona y metanol) mostrando actividad inhibitoria sobre las enzimas $\alpha$-amilasa y $\alpha$-glucosidasa cuyos menores valores de $\mathrm{IC}_{50}$ fueron obtenidos con la acetona $(21,85 \mathrm{y}$ 46,35 , respectivamente) ${ }^{18}$. Esto demuestra que el tipo de solvente influye en la extracción de los metabolitos inhibitorios presentes en la pulpa, lo que se refleja en los valores de $\mathrm{IC}_{50}$. Das et al. ${ }^{19}$ (2012) trabajaron con el extracto acuoso de la pulpa de 22 especies diferentes de frutas, donde las especies Phoenix sylvestris y a la Achras sapota tuvieron las mejores actividades inhibitorias con valores de $\mathrm{IC}_{50}$ de 5 y $53 \mu \mathrm{g} / \mathrm{mL}$, respectivamente para la enzima $\alpha$-amilasa y valores de $\mathrm{IC}_{50} 9$ y $56 \mu \mathrm{g} / \mathrm{mL}$, respectivamente sobre la enzima $\alpha$-glucosidasa. Un aspecto interesante de este trabajo es que los extractos de ambos frutos mostraron niveles bajos de polifenoles totales $(6,9$ y $1,5 \mathrm{mg}$ EAG/100g de muestra, respectivamente), con lo que los autores concluyeron que los componentes no fenólicos presentes en los frutos podrían ser los responsables de la actividad inhibitoria enzimática.

La propiedad inhibitoria in vitro sobre las enzimas $\alpha$-amilasa y $\alpha$-glucosidasa también fue estudiada con extractos no acuosos (metanol, acetato de etilo y diclorometano) con diferentes partes de la especie Annona muricata (fruta, hoja, corteza de tallo y de raíz), donde se reportaron valores de $\mathrm{IC}_{50}$ que variaron entre 1 a $27 \mu \mathrm{g} / \mathrm{mL}$. Asimismo, esos extractos mostraron una inhibición de tipo acompetitiva sobre dichas enzimas. Por otra parte, en el mismo estudio, la acetogenina aislada de la pulpa resulto ser un mejor inhibidor de esas enzimas que la metformina (fármaco utilizado en el tratamiento de la diabetes tipo II), por lo que los autores concluyeron que la acetogenina sería el posible responsable de la actividad inhibitoria sobre las enzimas $\alpha$-amilasa y $\alpha$-glucosidasa ${ }^{20}$.

Nuestro interés fue investigar el efecto inhibitorio que tienen las pulpas de los frutos tumbo serrano (Passiflora tripartita var. mollisima) y pitahaya amarilla (Hylocereus megalanthus) 
en su condición acuosa, ya que son usualmente consumidas por la población peruana en forma fresca y/o en jugos y a las que se les atribuye una acción hipoglicemiante. $\mathrm{El} \mathrm{IC}_{50}$ del extracto acuoso del tumbo serrano y de la acarbosa obtenidos, fueron cercanos, lo cual corroboraría que este fruto así consumido por la población tiene un efecto hipoglicemiante.

\section{Comportamiento de inhibición de las enzimas $\alpha$-amilasa y $\alpha$-glucosidasa}

Según el gráfico de Lineweaver-Burk el extracto acuoso de tumbo serrano mostró una inhibición de tipo no competitiva mixta y el extracto acuoso de pitahaya amarilla exhibió un comportamiento de tipo competitiva sobre la $\alpha$-glucosidasa (figuras $1 \mathrm{~b}$ y $1 \mathrm{c}$ ). Con respecto a la $\alpha$-amilasa solo se observó inhibición de tipo no competitiva mixta por parte del tumbo serrano (figura 1a).

Trabajos realizados con HPLC mostraron la presencia de flavonoides tipo orientin, vitexin, vicenin y schaftoside y otros en la pulpa del tumbo serrano ${ }^{21}$. Estos mismos flavonoides purificados de Phyllostachyz edulis han mostrado tener actividad inhibitoria sobre ambas enzimas de modo competitivo como es el caso del orientin y vitexin ${ }^{22}$. En nuestro caso el tipo de comportamiento inhibitorio no competitiva mixta se debería a la acción sinérgica de todos los metabolitos secundarios presentes en la P. tripartita var. mollisima.

El extracto acuoso de la Hylocereus megalanthus no presentó una buena actividad inhibitoria sobre las enzimas, logrando solo inhibir competitivamente a la enzima $\alpha$-glucosidasa, lo que podría deberse a la presencia de ácido gallico en la pulpa, el cual ha manifestado en otros estudios la capacidad de inhibir a la enzima en mención ${ }^{23}$. 

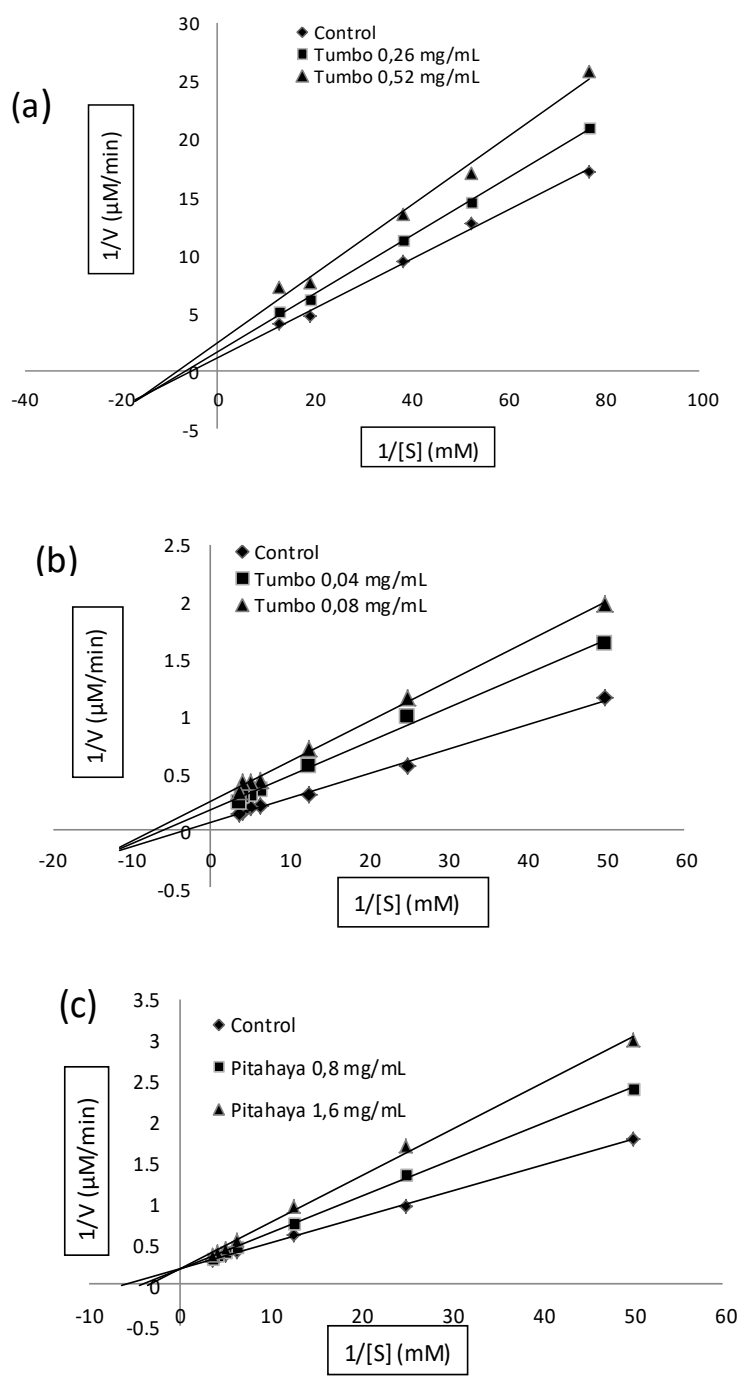

Figura 1. Análisis de diagramas de Lineweavere-Burk. (a) tumbo serrano (P. tripartita var. mollisima) frente $\alpha$-amilasa. (b) tumbo serrano (P. tripartita var. mollisima) frente $\alpha$-glucosidasa. (c) pitahaya amarilla (H. megalanthus) frente $\alpha$-glucosidasa.

La acarbosa, por su parte, mostró en este estudio un tipo de inhibición competitiva frente a la $\alpha$-glucosidasa y un tipo de inhibición no competitiva mixta frente a la $\alpha$-amilasa, resultados que son coincidentes con lo reportado por Kim et al. ${ }^{24}$. 
Tabla 3. Parámetros cinéticos y modo de inhibición de los extractos acuosos sobre las enzimas $\alpha$-amilasa y $\alpha$-glucosidasa

\begin{tabular}{|c|c|c|c|c|c|c|}
\hline & \multicolumn{3}{|c|}{$\alpha$-glucosidasa } & \multicolumn{3}{|c|}{$\alpha$-amilasa } \\
\hline $\begin{array}{c}\text { P. tripartita var. } \\
\text { mollisima }(\mathrm{mg} / \mathrm{mL})\end{array}$ & $\mathbf{0}$ & 0,04 & $\mathbf{0 , 0 8}$ & $\mathbf{0}$ & 0,26 & $\mathbf{0 , 5 2}$ \\
\hline $\mathrm{Km}$ & 0,30 & 0,16 & 0,13 & 0,19 & 0,16 & 0,12 \\
\hline $\mathrm{V}_{\text {máx. }}$ & 14,14 & 5,6 & 3,96 & 0,92 & 0,64 & 0,41 \\
\hline Tipo de inhibición & \multicolumn{3}{|c|}{ No competitiva mixta } & \multicolumn{3}{|c|}{ No competitiva mixta } \\
\hline H. megalanthus $(\mathrm{mg} / \mathrm{mL})$ & $\mathbf{0}$ & $\mathbf{0 , 8}$ & 1,6 & \multirow{3}{*}{\multicolumn{3}{|c|}{ ND }} \\
\hline $\mathrm{Km}$ & 0,16 & 0,24 & 0,31 & & & \\
\hline $\begin{array}{l}V_{\text {máx. }} \\
\text { Tipo de inhibición }\end{array}$ & 5,5 & $\begin{array}{c}5,5 \\
\text { Compet }\end{array}$ & 5,5 & & & \\
\hline
\end{tabular}

ND: no detectado

Los parámetros de $\mathrm{Km}$ y $\mathrm{V}_{\text {máx }}$ de los extractos acuosos de tumbo serrano y pitahaya se muestran en la tabla 3.

\section{CONCLUSIONES}

En el presente estudio el extracto acuoso del fruto tumbo serrano (P. tripartita var. mollisima) evidenció mayor capacidad inhibitoria sobre las enzimas $\alpha$-amilasa y $\alpha$-glucosidasa que la pitahaya amarilla (H. megalanthus). Nuestros resultados podrían contribuir al tratamiento complementario en pacientes con diabetes mellitus tipo II y también ser de interés en la industria alimentaria.

\section{AGRADECIMIENTO}

Un agradecimiento especial a los docentes de la sección de Maestría en Bioquímica de la Facultad de Medicina por su apoyo en el laboratorio del Centro de Investigación de Bioquímica y Nutrición de la UNMSM. 


\section{REFERENCIAS BIBLIOGRÁFICAS}

1. Bermúdez L, Cuéllar A, Abad M, Huamán J. Efecto hipoglucemiante de Gentianella bicolor (Wedd.) Fabris ex J.S. Pringle (Corpus Huay) en Sprague Dowley. Rev Cubana Plant Med. 2016; 21(1): 31-41.

2. Ministerio de Salud. Guía de Práctica Clínica para el Diagnóstico, Tratamiento y Control de la Diabetes Mellitus Tipo 2 en el Primer Nivel de Atención. Lima: Dirección de Prevención de Enfermedades No Transmisibles y Oncológicas; 2014.

3. Díaz M, Baiza L, Ibáñez M, Pascoe D, Guzmán A, Kumate J. Aspectos moleculares del daño tisular inducido por la hiperglucemia crónica. Gac Med Mex. 2004; 140(4): 437447.

4. Encina Zelada CR, Carpio Rivadeneira LJ. Máxima retención de ácido ascórbico, compuestos bioactivos y capacidad antioxidante en el néctar de tumbo. Ingenieria Industrial. 2011; 29: 225-245.

5. Loizzo MR, Lucci P, Núñez O, Tunids R, Balzano M, Frega NG, et al. Native Colombian Fruits and Their by-Products: Phenolic Profile, Antioxidant Activity and Hypoglycaemic Potential. Foods. 2019; 8(3): 89.

6. Kim H, Choi HK, Moon JY, Kim YS, Mosaddik A, Cho SK. Comparative antioxidant and antiproliferative activities of red and white pitayas and their correlation with flavonoid and polyphenol content. J Food Sci. 2011; 76(1): C38-45.

7. Wongsa P, Chaiwarit J, Zamaludien A. In vitro screening of phenolic compounds, potential inhibition against $\alpha$-amylase and $\alpha$-glucosidase of culinary herbs in Thailand. Food Chem. 2012; 131(3): 964-971.

8. Calixto M, Chire G, Orihuela C. Propiedades antioxidantes de chocolates comercializados en Perú. Acta Agron. 2018; 67(4): 479-485.

9. Wang $\mathrm{W}, \mathrm{Xu} \mathrm{H}$, Chen $\mathrm{H}$, Tai K, Liu F, Gao Y. In vitro antioxidant, anti-diabetic and antilipemic potentials of quercetagetin extracted from marigold (Tagetes erecta L.) inflorescence residues. J Food Sci Technol. 2016; 53(6): 2614-2624.

10. Contreras J, Calderón-Jaimes L, Guerra-Hernández E, García-Villanova B. Antioxidant capacity, phenolic content and vitamin $\mathrm{C}$ in pulp, peel and seed from 24 exotic fruits from Colombia. Food Res Int. 2011; 44(7): 2047-2053.

11. Rojano B, Zapata K, Cortés F. Capacidad atrapadora de radicales libres de Passiflora mollissima (Kunth) L. H. Bailey (curuba). Rev Cubana Plant Med. 2012; 17(4): 408419.

12. Carvajal de Pabon LM, Turbay S, Rojano B, Álvarez LM, Restrepo SL, Álvarez JM, et al. Algunas especies de Passiflora y su capacidad antioxidante. Rev Cubana Plant Med. 2011; 16 (4): $354-363$.

13. De Lima CA, Faleiro FG, Junqueira NTV, Cohen KO, Guimarães TG. Características físico-químicas, polifenóis e flavonoides amarelos em frutos de espécies de pitaias comerciais e nativas do cerrado. Rev Bras Frutic. 2013; 35(2):65-570.

14. Chauca M. Fenoles y capacidad antioxidante de guayaba (Psidium guajava), arándano (Vaccinium myrtillus) y fracciones comestibles y no comestibles de pitahaya (Selenicereus 
megalanthus) y aguaymanto (Physalis peruviana). [Tesis de Pregrado]. Chachapoyas: Universidad Nacional Toribio Rodríguez de Mendoza de Amazonas; 2019.

15. Choo W, Yong W. Antioxidant properties of two species of Hylocereus fruits. Adv Appl Sci Res. 2011; 2 (3): 418-425.

16. Rey D, Ospina L, Aragón M. Inhibitory effects of an extract of fruits of Physalis peruviana on some intestinal carbohydrases. Rev Colomb Cienc Quím Farm. 2015; 44(1): 72-89.

17. Song H, Chu Q, Xu D, Xu Y, Zheng X. Purified Betacyanins from Hylocereus undatus Peel Ameliorate Obesity and Insulin Resistance in High-Fat-Diet-Fed Mice. J Agric Food Chem. 2016; 64(1): 236-244.

18. Shanmugan S, Alcantara I, Denadai M, Dos Santos L, De Souza A, Narain N, et al. UHPLC-QqQ-MS/MS identification, quantification of polyphenols from Passiflora subpeltata fruit pulp and determination of nutritional, antioxidant, $\alpha$-amylase and $\alpha$-glucosidase key enzymes inhibition properties. Food Res Int. 2018; 108: 611-620.

19. Das S, Das S, De B. In vitro inhibition of key enzymes related to diabetes by the aqueous extracts of some fruits of West Bengal, India. Curr Nutr Food Sci. 2012; 8(1): 19-24.

20. Agu KC, Eluehike N, Ofeimun RO, Abile D, Ideho G, Ogedengbe MO, et al. Possible anti-diabetic potentials of Annona muricata (soursop): inhibition of $\alpha$-amylase and $\alpha$-glucosidase activities. Clin Phytosci. 2019; 5: 21.

21. Simirgiotis MJ, Schmeda-Hirschmann G, Bórquez J, Kennelly EJ. The Passiflora tripartita (Banana Passion) fruit: a source of bioactive flavonoid C-glycosides isolated by HSCCC and characterized by HPLC-DAD-ESI/MS/MS. Molecules. 2013;18(2):16721692.

22. Yang JP, He H, Lu YH. Four flavonoid compounds from Phyllostachys edulis leaf extract retard the digestion of starch and its working mechanisms. J Agric Food Chem. 2014; 62(31): 7760-7770.

23. Guevara M, Tejera E, Granda-Albuja MG, Iturralde G, Chisaguano-Tonato M, GrandaAlbuja S, et al. Chemical Caomposition and antioxidant activy of the main fruits consumed in the westerm coastal region of ecuador as source of health promoting compounds. Antioxidants (Basel). 2019; 8(9): 387.

24. Kim MJ, Lee SB, Lee HS, Lee SY, BAek JS, Kim D, et al. Comparative study of the inhibition of $\alpha$-glucosidase, $\alpha$-amylase, and cyclomaltodextrin glucanosyltransferase by acarbose, isoacarbose, and acarviosine-glucose. Arch Biochem Biophys. 1999; 371(2): 277-283. 